\title{
DERECHOS REALES Y BIENES REGISTRABLES EN EL DERECHO INTERNACIONAL PRIVADO
}

\author{
Milton C. Feuillade \\ CONICET, Universidad Nacional de Rosario, \\ Rosario, Santa Fe, Argentina \\ Contacto: miltonfeuillade@hotmail.com
}

Recibido: 4 de septiembre de 2020

Aprobado: 12 de octubre de 2020

Para citar este artículo:

Feuillade, M. C. (2021). "Derechos Reales y bienes registrables en el Derecho Internacional Privado". Prudentia Iuris, N. 91, pp. 183-201

DOI: https://doi.org/10.46553/prudentia.91.2021.pp.183-201

Resumen: Establecer un mismo régimen legal a los bienes sitos en el territorio garantiza condiciones uniformes y fácilmente conocibles y esto favorece la seguridad jurídica. El Código Civil y Comercial completa de forma coherente y sistémica la materia, que carecía anteriormente de estas características. La razonabilidad del foro del lugar de situación de los bienes está ligada a los mismos argumentos de la justificación del Derecho aplicable sobre cuestiones de carácter real que versen sobre bienes localizados en el territorio. En la propiedad inmaterial la aplicación de la territorialidad posee la finalidad práctica de evitar dilaciones y pruebas del Derecho extranjero para su protección. En bienes culturales debe partirse de una concepción amplia de ellos en el estándar de protección por su valor cultural y su consideración como patrimonio histórico, adhiriendo a la llamada tesis de las dos calificaciones.

Palabras clave: Derechos Reales, Derecho Internacional Privado, Bienes culturales. 


\title{
Property Law and Real Recordable in Private International Law
}

\begin{abstract}
Establishing the same legal regime for assets located in the territory guarantees uniform and easily knowable conditions and this favors legal security. The Civil and Commercial Code consistently and systemically completes the matter, which previously lacked these characteristics. The reasonableness of the forum of the place where the assets are located is linked to the same arguments for the justification of the applicable law on matters of a real nature that relate to assets located in the territory. In intangible property, the application of territoriality in this matter has the practical purpose of avoiding delays and evidence of foreign law for its protection. In cultural property, a broad conception of them must be started in the standard of protection due to their cultural value and their consideration as historical heritage, adhering to the so-called thesis of the two qualifications.
\end{abstract}

Keywords: Real Rights, Private International Law, Cultural heritage.

\section{Diritto immobiliare e reale registrabile nel diritto internazionale privato}

Sommario: Stabilire lo stesso regime giuridico per i beni situati nel territorio garantisce condizioni uniformi e facilmente conoscibili e questo favorisce la certezza del diritto. Il Codice Civile e Commerciale completa coerentemente e sistematicamente la materia, che in precedenza era priva di queste caratteristiche. La ragionevolezza del foro del luogo in cui si trovano i beni è collegata agli stessi argomenti di giustificazione della legge applicabile su questioni di natura reale che riguardano i beni situati nel territorio. Nella proprietà immateriale, l'applicazione della territorialità in questa materia ha lo scopo pratico di evitare ritardi e prove di diritto straniero per la sua tutela. Nei beni culturali, una concezione ampia degli stessi deve essere avviata nello standard di protezione per il loro valore culturale e la loro considerazione come patrimonio storico, aderendo alla cosiddetta tesi delle due qualifiche.

Parole chiave: Diritti Reali, Diritto Internazionale Private, Beni culturali. 


\section{Introducción}

En esta materia, la lex rei sitiae es una conexión prácticamente universalizada en inmuebles ${ }^{1}$, así es que uniformemente se utiliza en el sistema angloamericano ${ }^{2}$, como en los derechos internos de la Unión Europea; aunque cabe aclarar que a hoy no existe en la materia norma comunitaria como tal respecto del Derecho aplicable ${ }^{3}$, sí en cambio sobre competencia judicial internacional, declarada como exclusiva ${ }^{4}$.

En lo que hace a los bienes muebles, la lex rei sitiae no ha sido uniforme a lo largo del tiempo.

En nuestro Derecho, las influencias de Story fueron determinantes ${ }^{5}$. Este autor parte de los principios inmobilia reguntur lege loci ubi cita y mobilia sequuntur personam; por ello, al seguir los muebles a la persona deben ser regulados por la lex domicilii. Esta posición viene de los estatutarios ${ }^{6}$ y lo cierto es que fue tomada por Vélez Sarsfield y hoy perdura en el Código Civil y Comercial.

La fundamentación de la territorialidad ha estado basada en razones políticas y económicas, América Latina la mantuvo desde el Derecho español heredado ${ }^{7}$.

Vélez Sarsfield, en el comentario del artículo 2507, justificaba la aplicación de la ley territorial en la soberanía. Este argumento está ligado al Derecho Internacional Público y existen razones de protección del Estado respecto de la propiedad no solamente de bienes inmuebles, baste citar las limitaciones a la compra de inmuebles rurales por parte de personas extranjeras $^{8}$ o las restricciones sobre compras y transferencias de divisas.

1 Niboyet, J. (1951). Principios de Derecho Internacional Privado. $4^{\mathrm{a}}$ ed. México. Trillas, 198.

2 Symeonides, S. (2016). Choice of law. New York. Oxford University Press, 510.

3 Martiny, D. (2012). "Lex rei sitae as a connecting factor in EU private international law". Praxis des internationalen Privat - und Verfahrensrechts (IPRax). Jun - 2012 - № 2, 119$133,124$.

4 Originalmente lo encontrábamos en el art. 22 del Reglamento 44/2003, antiguo Bruselas I, hoy art. 24 del Reglamento 1215/2012.

5 Story, J. (1891). Comentarios sobre el conflicto de las leyes. Quiroga, C. (Trad.). T. 2. Buenos Aires. Lajouane, 308.

6 Meijers, E. (1934). "L'histoire des principes fondamentaux du droit international privé à partir du Moyen Age, spécialement dans l'Europe occidentale”. Recueil des Cours. T. 49, 544 a 686.

7 Samtleben, J. (2010). "El principio de territorialidad en América Latina”. En: Samtleben, J. (Coord.). Rechtspraxis und Rechtskultur in Brasilien und Lateinamerika. Shaker, Aacher, 370 a 405, 371. En Internet: https://es.scribd.com/document/245879982/Samtleben-ElPrincipio-de-Territorialidad-en-America-Latina, 3/3/2020.

$8 \quad$ Ley $\mathrm{N}^{\circ} 26.737$. 
Sólido argumento también es basarlo en razones económicas, la propiedad mueble e inmueble hace a la planificación y regulación de la actividad de los particulares en relación a la economía.

Por otra parte, establecer un mismo régimen legal a los bienes sitos en el territorio garantiza condiciones uniformes y fácilmente conocibles y esto favorece la seguridad jurídica ${ }^{9}$.

\section{Derecho convencional}

Por los motivos y fundamentos que hemos expuestos en la introducción, los marcos convencionales en esta materia son escasos.

Los Tratados de Montevideo de Derecho Civil de 1889 y 1940, en sus artículos 26 y 32, respectivamente, declaran si distinguir entre bienes muebles e inmuebles la aplicación del lugar donde existen en cuanto a su calidad, posesión, enajenabilidad absoluta o relativa, así como a todas las relaciones de Derecho de carácter real sobre las que son susceptibles.

En el Tratado de Derecho Civil de 1889, además, encontramos las siguientes regulaciones: 1) El artículo 27 establece que los buques situados en aguas no jurisdiccionales se reputan ubicados en el lugar de su matrícula. 2) Respecto de los cargamentos de buques en aguas no jurisdiccionales, por el artículo 28 se reputan situados en el lugar de destino definitivo de las mercaderías. 3) Los artículos 30 y 31 regulan el cambio de situación de los bienes muebles y establecen que el cambio de situación no afecta los derechos adquiridos, conforme a la ley del lugar donde se encontraban al tiempo de su adquisición. Y respeto de terceros, los derechos adquiridos por ellos, conforme a la ley del lugar de su nueva situación después del cambio operado y antes de llenarse los requisitos requeridos, priman sobre los del primer adquirente. 4) Respecto a la prescripción, tanto adquisitiva como extintiva, dice el artículo 52 que las acciones reales se rigen por la ley del lugar de situación del bien gravado. Y acorde al artículo 53, si el bien gravado fuere mueble y hubiese cambiado de situación, la prescripción se rige por la ley del lugar en que se haya completado el tiempo necesario para prescribir.

La jurisdicción internacional está contenida en el artículo 67, según el cual las acciones reales y las denominadas mixtas deben ser deducidas ante los jueces del lugar en el cual exista la cosa. Si existen varios bienes en diferentes jurisdicciones deben promoverse tantos juicios como lugares de situación existan.

9 González Campos, J. (1993). Derecho Internacional Privado. $5^{\text {a }}$ ed. Madrid. Eurolex. 
Respecto del Tratado de Montevideo de 1940, en el artículo 34 parte de la misma base, sin que varíen los efectos ante el cambio de situación de los bienes muebles adquiridos de conformidad a la ley del lugar donde existían al tiempo de su adquisición.

Aclara que respecto a la forma deben ser cumplidos los requisitos del lugar de situación. Finalmente, dispone que el cambio de lugar de la cosa mueble litigiosa, operado después de la promoción de la respectiva acción real, no modifica las reglas de competencia legislativa y judicial que originariamente fueron aplicables.

Por los artículos 52 y 54, la prescripción adquisitiva y extintiva se rige por la ley del lugar de situación. Si el bien fuese mueble y hubiese sido trasladado de lugar, la prescripción será regida por la ley del lugar en donde se haya completado el tiempo necesario para prescribir ${ }^{10}$.

Por el artículo 64, la jurisdicción corresponde al juez del lugar de situación de los bienes, sin distinción de su calidad.

\section{Derecho interno}

El Código Civil y Comercial sigue los mismos criterios que el Código de Vélez. Regula la jurisdicción y el Derecho aplicable, de bienes inmuebles, muebles, de situación permanente y los que carecen de ella, registrables y no registrables, con una norma dedicada a calificaciones y otra a su transferibilidad.

\section{A. Calificaciones}

El problema de las calificaciones en esta materia se encuentra regulado en el artículo 2663 del Código Civil y Comercial, cuando determina: "La calidad de bien inmueble se determina por la ley del lugar de su situación". La norma también debería haber referido a los otros bienes que contiene el título.

Sobre los bienes registrables, una opción es la aplicación analógica dentro del título, calificando el bien como registrable a partir de la ley del lugar de situación. Sin embargo, debe recordarse que conforme al artículo 2668 , éstos bienes son regidos por la ley del lugar de registro, por lo que creemos que desde allí debe surgir su calificación, por ser la lex causae.

10 Conforme a los arts. 53 y 55. 
La problemática surgirá sobre la registrabilidad y la calidad de la registración, por ejemplo, en bienes culturales y acciones sobre su restitución ${ }^{11}$.

La ley del lugar de situación es la lex causae, por lo que, si estamos ante muebles de situación permanente, el artículo 2669 califica diciendo: “[...] se conservan sin intención de ser transportados [...]"; si están en la república deberemos ir a los artículos 225, concordantes y sucesivos del Código Civil y Comercial.

En el caso de los bienes muebles, la calificación deberá realizarse desde el Derecho al que se arribe según cada caso concreto, conforme al artículo 2670 del Código Civil y Comercial.

Por otra parte, todo esto hace a si son de dominio público o no, bien de familia, etc. A ello se suman normas de aplicación inmediata que ingresan desde el artículo 2599 del Código Civil y Comercial, como los derechos sobre bienes de incidencia colectiva del artículo 240 del Código Civil y Comercial y las leyes especiales concordantes.

\section{B. Jurisdicción internacional}

La razonabilidad del foro del lugar de situación de los bienes está ligada a los mismos argumentos de la justificación del Derecho aplicable sobre cuestiones de carácter real que versen sobre bienes localizados en el territorio.

El Código Civil y Comercial, en el artículo 2609, declara jurisdicción exclusiva sobre los bienes inmuebles y más adelante dice, en el artículo 2664: "Los jueces del Estado en que están situados los inmuebles son competentes para entender en las acciones reales sobre dichos bienes". La exclusividad de la jurisdicción es sobre cuestiones que hagan a la cosa en su estricto carácter real. Debe recordarse que siempre debe interpretarse de forma restrictiva.

La norma bilateraliza dado que su redacción es general, es decir, no solamente los jueces argentinos poseen la jurisdicción sobre los inmuebles situados en la República, sino que consideramos los inhibe de asumir jurisdicción sobre aquellos que se encuentren en el extranjero. La consecuencia base será el no reconocimiento de decisorios cuando se infrinja la norma ${ }^{12}$.

11 Ochoa Jiménez, M. (2019). "Normas de Derecho Internacional Privado en materia de bienes: la regla lex rei sitae en América Latina y Colombia”. Revista de Derecho Privado. Nro. 37, 121 a 151, 128. En Internet: https://revistas.uexternado.edu.co/index.php/derpri/article/ view/6059/7777, 9/3/2020.

12 Feuillade, M. (2020), Derecho Internacional Privado. Buenos Aires. Astrea. 
Incluso si lo analizamos desde el foro de necesidad del artículo 2602 del Código Civil y Comercial, es una de las situaciones donde más claramente la sentencia será muy posiblemente ineficaz, aunque podría estar la posibilidad de que la viéramos casi de laboratorio.

A su vez, dice el artículo 2665 sobre los bienes registrables: "Los jueces del Estado en el que fueron registrados los bienes son competentes para entender en las acciones reales entabladas sobre dichos bienes". La jurisprudencia en este sentido era uniforme de vieja data ${ }^{13}$.

Dentro de los bienes registrables tenemos los buques y las aeronaves. Por un lado, establece el artículo 616: "Además de la competencia que les corresponda con arreglo a las leyes generales, los tribunales nacionales deben entender en todas las acciones derivadas del contrato de ajuste que fue 0 debió ser cumplido en un buque de bandera nacional".

Es opinión de una parte de la doctrina ${ }^{14}$ que si bien la norma habla de contrato de ajuste y no de acciones reales, al mencionar la bandera del buque está direccionando al lugar de registro.

Creemos que no hace falta este razonamiento. El buque es un bien registrable y le es aplicable el artículo 2665 de forma lisa y llana. Lo mismo cabe decir del artículo 199 o sus concordantes en el Código Aeronáutico, porque no hace falta aplicación analógica de norma, habiendo norma específica.

La pregunta sobre los bienes registrables es si esta jurisdicción es exclusiva, porque expresamente no se menciona. Una postura parte de la base de que poseen naturaleza jurídica similar a los inmuebles y, por lo tanto, debe ser exclusiva ${ }^{15}$. Lo cierto es que no son asimilados como inmuebles, tal como ocurre con los muebles de accesión permanente.

A ello se le suma el artículo 2609, inc. b), del Código Civil y Comercial, que declara jurisdicción exclusiva: "[...] en materia de validez o nulidad de las inscripciones practicadas en un registro público argentino”.

13 Casos: "D. Carlos Saguier c/ D. Francisco Cortina s/ Ejecución” (Fallos: 9:147); "Don José A. Martinelli y Otros c/ Don Meliton Panelo, en Juicio Ejecutivo Seguido ante los Tribunales de Montevideo s/ Mandamiento de Embargo y Cumplimiento de Exhorto" (Fallos: 89:381); "Exhorto de los Tribunales del Paraguay al Juez Letrado del Territorio Nacional de Formosa s/ Embargo de Bienes de Don Antonio Petirossi, Sitos en Formosa" (Fallos: 89:421); "Exhorto del Señor Juez de Comercio de Montevideo en los Autos Seguidos por Don Antonio Becco c/ Radivoj y Cía., por Cobro de Crédito Hipotecario" (Fallos: 192:295).

14 Noodt Taquela, M.; Argerich, G. (2014). "Título IV: Disposiciones de Derecho Internacional Privado, Capítulo 3: Parte especial. Sección 15: Derechos Reales". En Rivera, Julio C.; Medina, Graciela (Dirs.). Código Civil y Comercial de la Nación comentado. T. 6, Buenos Aires. La Ley, 977.

15 Iñiguez, M. (2015). “Comentario del artículo 2665”. En: AA. VV. Código Civil y Comercial de la Nación Comentado. T. VI. Buenos Aires. Infojus, 430. 
El punto es que no refiere a las acciones reales, es decir, estamos en lo mismo que con los buques y las aeronaves.

Pensamos que se trata de jurisdicción única, no exclusiva, que, como dijimos, debe interpretarse de forma restrictiva. Las consecuencias son diferentes, porque abre la puerta al reconocimiento de otra jurisdicción extranjera diferente que para el caso en que resulte razonable, no exorbitante, efectiva y justa, como se estableció en "Behrens"16, así como la eventual aplicación del foro de necesidad del artículo 2602 del Código Civil y Comercial.

Sobre propiedad inmaterial, el artículo 2609, inc. c), establece: “[...] en materia de inscripciones o validez de patentes, marcas, diseños o dibujos y modelos industriales y demás derechos análogos sometidos a depósito o registro, cuando el depósito o registro se haya solicitado o efectuado o tenido por efectuado en Argentina".

Aquí la literalidad es diferente, porque puede advertirse que habla de "derechos análogos", de lo cual pueden inferirse las acciones reales. También debe tenerse en cuenta que la exclusividad se fundamenta en que la inscripción en la propiedad industrial posee carácter constitutivo, a diferencia de lo que ocurre con los derechos de autor.

Para los bienes muebles no registrables, la jurisdicción es concurrente en dos foros a opción del actor, cuando el artículo 2666 sienta: "Los jueces del domicilio del demandado o del lugar de situación de los bienes no registrables son competentes para entender en las acciones reales sobre dichos bienes"17. Lo que por supuesto habilita la prórroga de jurisdicción en los términos del artículo 2605 del Código Civil y Comercial.

\section{Derecho aplicable}

Por el artículo 2667 del Código Civil y Comercial, los Derechos Reales sobre inmuebles se rigen por la ley del lugar de su situación. Respecto a los bienes muebles registrables, conforme al artículo 2668, se rigen por el Derecho del Estado de registro.

16 SCBA, 13/6/2007, "Behrens, Germán Federico o Hermann Friedrich s/ sucesión ab intestato".

17 La calificación que se haga del bien tendrá incidencia sobre la jurisdicción dado el discernimiento de su calidad de inmueble o mueble y, en su caso, de su situación permanente o no, y destacable es el caso "Dumas de Castex, Luisa P. (suc.)", JA, 1992 - II, pp. 311-317, donde se establece el carácter no permanente del dinero depositado y a contrario el carácter permanente a las acciones depositadas en un Banco y si esos bienes están en el extranjero los tribunales nacionales no asumen jurisdicción respecto de ellos. 
Lo mismo establecen los artículos 597 y 598 de la Ley de la Navegación $\mathrm{N}^{\circ} 20.094$, donde la ley de bandera es la de registro, igual que los artículos 38 y 40 del Código Aeronáutico sobre la nacionalidad de aeronaves.

En relación a los muebles que tienen situación permanente, nos dice el artículo 2669 del Código Civil y Comercial: "Los Derechos Reales sobre muebles que tienen situación permanente y que se conservan sin intención de transportarlos, se rigen por el Derecho del lugar de situación en el momento de los hechos sobre los que se plantea la adquisición, modificación, transformación o extinción de tales derechos. El desplazamiento de estos bienes no influye sobre los derechos que han sido válidamente constituidos bajo el imperio de la ley anterior".

Un tema es el contenido y alcance del concepto: “[...] sin intención de transportarlos [...]"; la jurisprudencia se ha inclinado por la apreciación del caso concreto a partir de la naturaleza del bien, la intención y comportamiento del propietario respecto de permanencia en la Argentina ${ }^{18}$.

La parte final del artículo resuelve el conflicto móvil anclando el momento en que debe tomarse el lugar de situación. La solución es la misma que la de los artículos 30 y 34 de los Tratados de Montevideo de 1889 y 1940, respectivamente.

Consideramos que esta es una regla complementaria específica del artículo 2595, inc. b), del Código Civil y Comercial, cuando resuelve el conflicto inter-temporal.

En relación a los Derechos Reales sobre bienes muebles que carecen de situación permanente, establece el artículo 2670: "Los Derechos Reales sobre los muebles que el propietario lleva siempre consigo o los que son de su uso personal, esté o no en su domicilio, como también los que se tienen para ser vendidos o transportados a otro lugar se rigen por el Derecho del domicilio de su dueño. Si se controvierte o desconoce la calidad de dueño, se aplica el Derecho del lugar de situación".

El sistema argentino hoy sigue el de Vélez Sarsfield, con influencias de Story, por el que los muebles de situación permanente se rigen por la ley de lugar de situación y todo otro por la ley del domicilio del propietario.

Sobre los bienes para ser vendidos o transportados, se parte de la base de que no poseen lugar de situación definitiva o establemente previsible y se ha tenido desde Savigny la determinación en la ley personal del propietario $^{19}$.

18 Caso: "Stanford, Sarita c/ Stanford, Carlos E. (suc.)", CCiv., Sala 1ª , JA - 1942 - I - 715.

19 López Herrera, F. (1995). "El régimen de los bienes muebles en el Derecho Internacional Privado". Revista de la Facultad de Derecho de la Universidad Central de Venezuela, Nro. $3,39-54,41$. 
Posteriormente se ha promovido como punto de contacto la ley del lugar de destino de los bienes. Se argumenta que en ese lugar es donde la cosa alcanza su situación estable, pero lo cierto es que el lugar de destino puede modificarse o el bien nunca arribar.

\section{Transmisión de derechos}

El párrafo segundo del artículo 2667 del Código Civil y Comercial establece: "Los contratos hechos en un país extranjero para transferir Derechos Reales sobre inmuebles situados en la República, tienen la misma fuerza que los hechos en el territorio del Estado, siempre que consten en instrumentos públicos y se presenten legalizados". Sigue el mismo criterio y prácticamente reproduce la original redacción de Vélez Sarsfield en el artículo $1211^{20}$.

La transmisión de Derechos admisibles son los enumerados en el artículo 1887 del Código Civil y Comercial en su númerus clausus, como consecuencia de la calificación desde el lugar donde el bien se encuentra sito. Lo mismo cabe decir sobre el efectivo modo de adquisición, regulado en el artículo 1892 y concordantes del cuerpo normativo.

A su vez, nos parece correcto considerar la bilateralización de la norma, por lo que a nuestro criterio nada obstaría a la realización de contratos en la Argentina que transfieran Derechos Reales no declarados como tales en nuestra legislación o con diferente regulación, si cumplen con la ley extranjera y sus formas poseen equivalencia.

El documento debe ser realizado por instrumento público, lo que implica que no necesariamente lo confeccionará un notario sino un funcionario que pueda dar fe pública.

El asunto aquí es la calificación de instrumento público, que es un problema de ley sustancial, el cual no debe confundirse con la forma.

La calificación deberá hacerse desde la lex causae; si en el lugar de otorgamiento dicho instrumento en cuanto al fondo debe reconocerse, luego, respecto a la forma se estará por los parámetros del artículo 2649, el instrumento público es una ley impositiva y en su caso tendrá que analizarse en la Argentina su equivalencia.

20 Decía la norma: "Art. 1211. Los contratos hechos en país extranjero para transferir derechos reales sobre bienes inmuebles situados en la República, tendrán la misma fuerza que los hechos en el territorio del Estado, siempre que constaren de instrumentos públicos y se presentaren legalizados. Si por ellos se transfiriese el dominio de bienes raíces, la tradición de éstos no podrá hacerse con efectos jurídicos hasta que estos contratos se hallen protocolizados por orden de un juez competente". 
La intervención de notario público en el extranjero hace presumir la legalidad del acto y el cumplimiento de las leyes del país del cual emana ${ }^{21}$.

Respecto del Derecho aplicable, es categórica la aplicación de la ley argentina y la norma se circunscribe a la forma. Sin embargo, sobre el fondo, si el derecho transmitido requiere protocolización o cualquier tipo de registración en el país, debe realizarse conforme a los artículos 1890 y 1892 del Código Civil y Comercial y la Ley $\mathrm{N}^{\mathrm{o}} 17.801$ de Registración de propiedad inmueble ${ }^{22}$.

El requisito de legalización es común a todo instrumento o documento público que se pretenda hacer valer en el país, no será objeto de este trabajo este análisis ${ }^{23}$.

El régimen del anterior Código Civil exigía en el artículo 1211 que estos contratos de transferencia de dominio, para tener plenos efectos jurídicos, debían ser protocolizados por orden de juez competente. Así estaba originalmente proyectado en el Código Civil y Comercial y se quitó.

Es opinión de $\mathrm{Uzal}^{24}$, que la norma hacía al resguardo de la seguridad del tráfico inmobiliario mediante el control judicial, y debe ser suplida de algún modo, sugiriendo la sede registral como arbitradora de los mecanismos para que se preserven la integridad y buena fe, así como el control fiscal de las operaciones.

\section{Propiedad inmaterial}

La aplicación de la territorialidad en esta materia posee la finalidad práctica de evitar dilaciones y pruebas del Derecho extranjero para su protección ${ }^{25}$. Así, desde antiguo lo establece el Convenio de Berna en el artículo $5^{\circ}$, a partir de la protección desde la ley donde se la reclama. En la misma

21 Pérez, A. P. (1992). "Multipropiedad y Derecho Internacional Privado. Admisibilidad del contrato celebrado en el extranjero". Revista Notarial - Colegio de escribanos de la provincia de Córdoba. Nro. 63, 1-9, 3 y jurisprudencia allí citada.

22 Herrera, M. (2012). "Poderes y transferencia de Derechos Reales sobre inmuebles en el proyecto de unificación de los Códigos Civil y Comercial de 2012, desde la perspectiva del Derecho Internacional Privado". Revista del Notariado. Vol. 910, 99-120, 110. 820 .

23 Feuillade, M. (2007). "Los documentos extranjeros en el proceso". LL - 2007 - F, 805 a

24 Uzal, M. (2015). Derecho Internacional Privado. Buenos Aires. La Ley, 484.

25 Lipszyc, D. (2014). "La resolución de conflictos sobre ley aplicable y jurisdicción competente por infracción al Derecho de autor y conexos en Internet”. En: Lipszyc, D. (Coord.). Derechos de autor y cuestiones actuales, Revista Jurídica de Buenos Aires, I, 153 a 185, 155. 
línea están el resto de los Tratados posteriores, como el Tratado de OMPI sobre Derecho de Autor - TODA/WTC ${ }^{26}$.

En el sistema del Tratado de Montevideo sobre Propiedad Literaria y Artística de 1889 se establece en el artículo $2^{\circ}$ : "El autor de toda obra literaria o artística y sus sucesores gozarán en los Estados signatarios de los derechos que les acuerde la ley del Estado en que tuvo lugar su primera publicación o distribución", principio que se aleja del seguido modernamente, llamado del "trato nacional", donde se aplica a las obras extranjeras la misma ley que a las nacionales, originando un mosaico de leyes protectoras de una sola obra. Del principio de la lex loci originis sentado en Montevideo se infiere que excepto que se opte por el domicilio del demandado, es ante el juez del Estado de su primera publicación ante el que se debe acudir ${ }^{27}$. De todas maneras, si estamos ante un hecho dañoso producido en la República los jueces nacionales asumirán competencia ${ }^{28}$ y así está reconocido en el artículo 11 del Convenio, por el que en caso de fraude: "Las responsabilidades en que incurran los que usurpen el derecho de propiedad literaria o artística se ventilarán ante los tribunales y se regirán por las leyes del país en que el fraude se ha cometido"; incluso si no están reconocidos en el país de inscripción y según las leyes argentinas ante el reclamo la obra merece protección, los jueces asumirán competencia aplicando el forum causae ${ }^{29}$.

La Ley $\mathrm{N}^{\circ} 11.723$ de Propiedad Intelectual, en sus artículos 13 a 15, protege de forma amplia las obras publicadas en el extranjero; para ello, debe acreditar la registración en el exterior; en lo temporal, la protección es la que señale la ley extranjera, sin que pueda ser mayor a la ley local.

En el Derecho interno, la norma general es el artículo 2668, por lo que se aplica el Derecho del lugar de registro. Lo mismo cabe decir de la jurisdicción internacional y nos remitimos a lo ya expresado.

26 Para un análisis detallado de los diferentes marcos convencionales remitimos a: Lipszyc, D. (2017). Derecho de autor y derechos conexos. Bogotá. CERLALC. En especial, ver: la Convención Interamericana de Washington sobre derechos de autor en trabajos literarios científicos y artísticos, la Convención Universal de Ginebra, la Convención de Ginebra para la Protección de los Productores de Fonogramas contra la reproducción no autorizada, el Acuerdo de la OMC de Marrakech de 1994, que contiene la AADPIC ratificado en 1995 y el Tratado OMPI celebrado en Ginebra en 1996 sobre derechos de autor y sobre interpretación de fonogramas, ratificado en 1999.

27 Armando, M.; Lipszyc, D. (2003). "Bienes inmateriales". En: Fernández Arroyo, D. (Coord.). Derecho Internacional Privado de los Estados del Mercosur. Buenos Aires. Zavalia, 927.

28 Así lo ha declarado la jurisprudencia del caso: "Maroni, Enrique P. y otra c/ Mattos Rodríguez Gerardo H.”. Cámara Civil 1ª de la Capital, el 8 de junio de 1948. JA - 1948 - III, 553 a 563 . 1992.

29 CSJN, "Kaufman, Julio c/ Sociedad General de Autores", dictado el $1^{\circ}$ de setiembre de 
En la materia pasa a tener un rol fundamental el lugar de la inscripción registral de los derechos que, en muchos casos, presenta un carácter no sólo probatorio, sino constitutivo, configurándose como una condición de nacimiento y explotación de los propios derechos ${ }^{30}$; las acciones incluyen, por supuesto, la validez de las inscripciones o derecho sometido a registro y se extiende sobre lo referente a los Derechos Reales, conforme al artículo 2668 del Código Civil y Comercial; pero no se extiende, por ejemplo, a cuestiones sustantivas referidas a la titularidad de tales derechos, acciones de reclamación por daños, cesión o transmisión de derechos. Ante estas cuestiones, una solución estaría, por un lado, en la aplicación de los foros en materia contractual cuando la naturaleza de la cuestión lo permita, incluso para aquellos derechos que no nacen de un registro, sino que poseen su fuente en un contrato, tales como el know how o el trade secrets.

Cabe hacer algunas menciones sobre la propiedad industrial. Su territorialidad es mayor porque su registro posee carácter constitutivo, a diferencia de los derechos de autor. Posee un fuerte componente de orden público en la verificación que el Estado realiza de requisitos y formalidades que hacen a la economía o salud pública, entre otras muchas cosas.

\section{Bienes culturales}

Desde el Código Civil y Comercial el valor cultural está contemplado en el artículo 240, al regular las limitaciones de los bienes de incidencia colectiva; y la declaración de dominio público de las ruinas y yacimientos arqueológicos y paleontológicos, en el artículo 235, inc. f).

El registro del Patrimonio Cultural está regulado en la Ley $\mathrm{N}^{\circ}$ 25.197. Se parte de la base de que el Estado fija las normas de protección de forma exclusiva respecto de sus bienes culturales y la calificación de tales se hará según la lex fori; sin embargo, posturas doctrinarias establecen que debe partirse de una concepción amplia de ellos en el estándar de protección por su valor cultural y su consideración como patrimonio histórico, adhiriendo a la llamada tesis de las dos calificaciones ${ }^{31}$.

En la circulación de bienes culturales hay diferentes actores con intereses algunas veces contrapuestos, el comprador y vendedor que pretenden

30 Fernández Rozas, J.; Sánchez Lorenzo, S. (1999). Derecho Internacional Privado. Madrid. Civitas, 368.

31 Carrillo Carrillo, B. (2001). “Tráfico internacional ilícito de bienes culturales y Derecho Internacional Privado". Anales de Derecho. Universidad de Murcia. Nro., 205 a 234, 208. En Internet: https://digitum.um.es/digitum/bitstream/10201/11324/1/AD19\%202001\%20p\%20 1205234.pdf, 10/3/2020. 
mayor libertad de circulación. El poseedor de buena fe de un bien cultural trasladado ilícitamente que pretende su conservación o el propietario desposeído que solicita la restitución. Y los intereses del Estado, donde se dan tradicionalmente situaciones de "importadores" y "exportadores" de bienes culturales $^{32}$, donde se tensiona aquellos que pretenden la protección del Patrimonio histórico.

Se parte de la base de que el comercio de bienes culturales está sujeto a normas de policía que lo limitan ${ }^{33}$.

Países como España poseen constitucionalmente regulada la conservación del patrimonio cultural, en este caso, en el artículo 56.

La Ley $\mathbf{N}^{\circ} 24.633$ regula la circulación internacional de obras de arte, tanto en lo que hace a la importación como a la exportación, sean los artistas nacionales o extranjeros.

$\mathrm{El}$ artículo $1^{\circ}$ establece la calificación de obra de arte, la cual es de amplia descripción, al punto que en su parte final establece: "En todos los casos, la autoridad de aplicación será quien defina el encuadre de un bien como obra de arte incluida en las categorías previamente mencionadas".

No son obras de arte, de forma general, las reproducciones y las realizaciones artísticas a mano sobre piezas provenientes de procedimientos industriales en serie ${ }^{34}$.

La ley diferencia entre exportaciones e importaciones definitivas y temporarias, con marcos de exenciones aduaneras y el procedimiento para realizar la operatoria ${ }^{35}$. El órgano de aplicación es la Dirección Nacional de Bienes Culturales ${ }^{36}$.

En el caso de bienes culturales, es común la aplicación de normas de policía de dos países y de terceros países ${ }^{37}$.

Si hacemos una clasificación en categoría, puede hablarse de bienes: inexportables, exportables previa autorización, exportables temporalmente ${ }^{38}$.

En los marcos convencionales tenemos la Convención de la UNESCO sobre las medidas que deben adoptarse para prohibir e impedir la importa-

32 Fuentes Camacho, V. (1993). El tráfico ilícito internacional de bienes culturales. Madrid. Eurolex, 101. bra, 390 .

33 Lagarde, P. (1985). Le commerce de l'art en Droit International Privé français. Gine-

34 Conf. el art. $2^{\circ}$.

35 Conf. a los arts. $3^{\circ}$ y sigs.

36 En Internet: https://www.argentina.gob.ar/cultura/patrimonio/bienes-y-sitios, 10/3/2020.

37 López Carceller Martínez, P. (2001). La reivindicación de los bienes culturales muebles ilegalmente exportados. Valencia. Tirant lo Blanch "colección privado", 19.

38 Byrne Sutton, Q. (1988). Le trafic international de biens culturels sous l'angle de leur revendication par l'Etat d'origine. T. VII. Zurich. Schulthess, 9 a 34, 14. 
ción, la exportación y la transferencia de propiedad ilícita de bienes culturales, hecha en París, el 14 noviembre de 1970.

También tenemos el Convenio de Unidroit sobre los bienes culturales robados o exportados ilícitamente, hecho en Roma, el 24 de junio de 1995, aprobado por Ley $\mathrm{N}^{\circ} 25.257^{39}$.

Este Tratado regula la cooperación internacional en la materia de modo general y, en especial, los no regulados en el Convenio de París de 1970.

En primer lugar, abandona la aplicación de la lex rei sitiae y la cambia por la lex originis. Establece el principio general de restitución del bien. Se distingue la situación de un bien robado o si ha sido exportado sin las correspondientes autorizaciones ${ }^{40}$.

Respecto a los terceros adquirientes de buena fe posee en el Estado de recepción derecho a indemnización ${ }^{41}$.

Los derechos adquiridos por terceros de buena fe generan aplicaciones sucesivas de leyes que posiblemente no tienen los mismos derechos sobre el bien. Han tenido un caso testigo en Inglaterra. La jurisprudencia es Winkworth v. Christie ${ }^{42}$, donde los derechos adquiridos en un tercer país debieron ser reconocidos en el país de origen.

Trataba de obras de arte que habían sido robadas en Inglaterra y vendidas en Italia. Posteriormente, el adquiriente italiano las lleva a Londres para su venta mediante entrega a una conocida empresa del rubro. El dueño las reconoce y reclama su devolución.

El comprador italiano se niega a ello, alegando ser el legítimo propietario de las obras, pues según el Derecho italiano el adquiriente de buena fe, como este era el caso, hace suya la propiedad de la cosa mueble vendida.

El conflicto es determinar la legítima propiedad de las obras; según el Derecho italiano, rige la lex rei sitiae al momento de la adquisición del bien; aquéllas se encontraban en el mencionado país en ese tiempo. Allí fueron compradas y entregadas. Cuando el bien regresa a Inglaterra lo hace con un nuevo título de propiedad sobre él. El Tribunal reconoció, pues, la propiedad adquirida en Italia. El anterior propietario desposeído no puede reclamar las obras de arte frente al nuevo propietario, tercero de buena fe.

39 EnInternet:http://servicios.infoleg.gob.ar/infolegInternet/anexos/60000-64999/63763/ norma.htm, 11/3/2020.

40 Conf. los arts. $3^{\circ}$ y $5^{\circ}$.

41 Conf. los arts. $4^{\circ}$ y $6^{\circ}$.

42 Caso: Winkworth v. Christie Manson and Woods Ltd. and Another [1980] 1 ER (Ch) 496, [1980] 1 All ER 1121. En Internet: http://www.ifar.org/case_summary.php?docid=1192827443, $11 / 3 / 2020$. 
La problemática de la aplicación de este punto de contacto es la generación de un efecto purga sobre la titularidad anterior, por lo que la lex rei sitiae favorece el tráfico. Es por ello que la Convención aplica la ley de origen y sobre el tercero de buena fe establece un derecho de resarcimiento ${ }^{43}$.

Por ejemplo, establece el Derecho español en el artículo 464 del Código Civil que los bienes culturales pertenecen al Estado español y son inalienables e imprescriptibles. Se deja de lado la lex rei sitiae extranjera donde ha sido adquirido el bien, haya sido o no por un tercero de buena fe y opera como una norma de policía. Es a la Administración del Estado a quien corresponde realizar los actos conducentes a la total recuperación de los bienes ilegalmente exportados, aunque, tras haber sido recuperado el bien cultural por el Estado español como propietario del mismo, el anterior titular del bien cultural podrá solicitar su cesión del Estado. Para ello deberá acreditar la pérdida o sustracción previa del bien, obligándose a abonar el importe de los gastos derivados de su recuperación, y, en su caso, el reembolso del precio que hubiere satisfecho el Estado al adquirente de buena $\mathrm{fe}^{44}$.

\section{Conclusiones}

El establecer un mismo régimen legal a los bienes sitos en el territorio garantiza condiciones uniformes y fácilmente conocibles y esto favorece la seguridad jurídica.

En materia de calificaciones, el artículo 2663 debería haber referido a los otros bienes que regula el título. Sobre los bienes registrables una opción es la aplicación analógica, calificando el bien como registrable a partir de la ley del lugar de situación. En el caso de los bienes muebles, la calificación deberá realizarse desde el Derecho al que se arribe según cada caso concreto, conforme al artículo 2670 del Código Civil y Comercial.

La razonabilidad del foro del lugar de situación de los bienes está ligada a los mismos argumentos de la justificación del Derecho aplicable sobre cuestiones de carácter real que versen sobre bienes localizados en el territorio.

43 González Campos, J.; Virgós Soriano, M. (1988). "Law and Practice of International Art Trade in Spain”. En: International Sales of Works of Art. Ginebra, 333 y sigs.

44 Conf. art. 29 de la Ley española de protección de los bienes culturales. En similar sentido: Convención de la UNESCO hecha en París el 14 de noviembre 1970 y la Directiva 93/7/ CEE desarrollada en España por la Ley Nº 36/1994, y el Convenio UNIDROIT de 1995. 
En el régimen del anterior Código Civil se exigía en el artículo 1211 que estos contratos de transferencia de dominio, para tener plenos efectos jurídicos, debían ser protocolizados por orden de juez competente. La norma hacía al resguardo de la seguridad del tráfico inmobiliario mediante el control judicial por el que debe ser suplida de algún modo, sugiriendo la sede registral como arbitradora de los mecanismos para que se preserven la integridad y buena fe, así como el control fiscal de las operaciones.

En la propiedad inmaterial, la aplicación de la territorialidad en esta materia posee la finalidad práctica de evitar dilaciones y pruebas del Derecho extranjero para su protección. En el Derecho interno, la norma general es el artículo 2668.

En bienes culturales, debe partirse de una concepción amplia de ellos en el estándar de protección por su valor cultural y su consideración como patrimonio histórico, adhiriendo a la llamada tesis de las dos calificaciones.

Acorde a la legislación vigente, consideramos que debe partirse de un concepto amplio en el estándar de protección de los bienes culturales. El comercio de bienes culturales está sujeto a normas de policía que lo limitan y coincidimos con ello, incluso en la aplicación de normas de aplicación inmediata de terceros países. Es una situación particular donde debe primar el carácter restrictivo ante la posibilidad de daños irreparables a nivel sociocultural. La problemática de la aplicación de la lex rei sitiae al momento de la adquisición del bien cultural puede generar un efecto purga sobre la titularidad, y favorecer el tráfico.

Nos volcamos entonces por el criterio de que los bienes culturales, por principio general, pertenecen al Estado y son inalienables e imprescriptibles, por lo que se deja de lado la lex rei sitiae extranjera.

\section{Bibliografía}

Armando, M.; Lipszyc, D. (2003). "Bienes inmateriales". En: Fernández Arroyo, Diego (Coord.). Derecho Internacional Privado de los Estados del Mercosur. Buenos Aires. Zavalia, 927.

Byrne Sutton, Q. (1988). Le trafic international de biens culturels sous l'angle de leur revendication par l'Etat d'origine. T. VII. Zurich. Schulthess, 9 a 34, 14.

Carrillo Carrillo, B. (2001). "Tráfico internacional ilícito de bienes culturales y Derecho Internacional Privado". Anales de Derecho. Universidad de Murcia. Nro. 19, 205 a 234, 208. En Internet: https://igitum.um.es/digitum/bitstream/10201/11324/1/ AD19\%202001\%20p\%201205234.pdf, 10/3/2020.

Fernández Rozas, J.; Sánchez Lorenzo, S. (1999). Derecho Internacional Privado. Madrid. Civitas, 368.

Feuillade, M. (2020). Derecho Internacional Privado. Buenos Aires. Astrea. 
Feuillade, M. (2007). "Los documentos extranjeros en el proceso". LL - 2007 - F, 805 a 820 .

Fuentes Camacho, V. (1993). El tráfico ilícito internacional de bienes culturales. Madrid. Eurolex, 101.

González Campos, J.; Virgós Soriano, M. (1988). "Law and Practice of International Art Trade in Spain”. En: International Sales of Works of Art. Ginebra, 333 y sigs.

González Campos, J. (1993). Derecho Internacional Privado. $5^{a}$ ed. Madrid. Eurolex.

Herrera, M. (2012). "Poderes y transferencia de Derechos Reales sobre inmuebles en el proyecto de unificación de los Códigos Civil y Comercial de 2012, desde la perspectiva del Derecho Internacional Privado". Revista del Notariado. Vol. 910, 99-120, 110.

Iñiguez, M. (2015). “Comentario del artículo 2665”. En: AA. VV. Código Civil y Comercial de la Nación Comentado. T. VI. Buenos Aires. Infojus, 430.

Lagarde, P. (1985). Le commerce de l'art en Droit International Privé français. Ginebra, 390 .

Lipszyc, D. (2014). "La resolución de conflictos sobre ley aplicable y jurisdicción competente por infracción al Derecho de autor y conexos en Internet”. En: Lipszyc, D. (Coord.). Derechos de autor y cuestiones actuales, Revista Jurídica de Buenos Aires, I, 153 a 185, 155.

Lipszyc, D. (2017). Derecho de autor y derechos conexos. Bogotá. CERLALC.

López Carceller Martínez, P. (2001). La reivindicación de los bienes culturales muebles ilegalmente exportados. Valencia. Tirant lo Blanch "colección privado", 19.

López Herrera, F. (1995). "El régimen de los bienes muebles en el Derecho Internacional Privado". Revista de la Facultad de Derecho de la Universidad Central de Venezuela, Nro. 3, 39-54, 41.

Martiny, D. (2012). "Lex rei sitae as a connecting factor in EU private international law". Praxis des internationalen Privat - und Verfahrensrechts (IPRax). Jun 2012 - No 2, 119-133, 124.

Meijers, E. (1934). "L'histoire des principes fondamentaux du droit international privé à partir du Moyen Age, spécialement dans l'Europe occidentale”. Recueil des Cours. T. 49, 544 a 686.

Niboyet, J. (1951). Principios de Derecho Internacional Privado. $4^{\mathrm{a}}$ ed. México. Trillas, 198.

Noodt Taquela, M.; Argerich, G. (2014). “Título IV: Disposiciones de Derecho Internacional Privado, Capítulo 3: Parte especial. Sección 15: Derechos Reales”. En: Rivera, Julio C.; Medina, Graciela (Dirs.). Código Civil y Comercial de la Nación comentado. T. 6. Buenos Aires. La Ley, 977.

Ochoa Jiménez, M. (2019). "Normas de Derecho Internacional Privado en materia de bienes: la regla lex rei sitae en América Latina y Colombia". Revista de Derecho Privado. Nro. 37, 121 a 151, 128. En Internet: https://revistas.uexternado.edu.co/ index.php/derpri/article/view/6059/7777, 9/3/2020.

Pérez, A. P. (1992). "Multipropiedad y Derecho Internacional Privado. Admisibilidad del contrato celebrado en el extranjero". Revista Notarial - Colegio de escribanos de la provincia de Córdoba. Nro. 63, 1-9, 3 y jurisprudencia allí citada. 
Samtleben, J. (2010). "El principio de territorialidad en América Latina”. En: Samtleben, J. (Coord.). Rechtspraxis und Rechtskultur in Brasilien und Lateinamerika. Shaker. Aacher, 370 a 405, 371. En Internet: https://es.scribd.com/document/245879982/Samtleben-El-Principio-de-Territorialidad-en-America-Latina, $3 / 3 / 2020$.

Story, J. (1891). Comentarios sobre el conflicto de las leyes. Quiroga, C. (Trad.). T. 2. Buenos Aires. Lajouane, 308.

Symeonides, S. (2016). Choice of law. New York. Oxford University Press, 510.

Uzal, M. (2015). Derecho Internacional Privado. Buenos Aires. La Ley, 484. 